\title{
Dietary supplementation with probiotics during late pregnancy: outcome on vaginal microbiota and cytokine secretion
}

Beatrice Vitalii ${ }^{1 *}$, Federica Cruciani ${ }^{1}$, Maria Elisabetta Baldassarre ${ }^{2}$, Teresa Capursi ${ }^{2}$, Enzo Spisni ${ }^{3}$, Maria Chiara Valerii $^{3}$, Marco Candela', Silvia Turroni ${ }^{1}$ and Patrizia Brigidi ${ }^{1}$

\begin{abstract}
Background: The vaginal microbiota of healthy women consists of a wide variety of anaerobic and aerobic bacterial genera and species dominated by the genus Lactobacillus. The activity of lactobacilli helps to maintain the natural healthy balance of the vaginal microbiota. This role is particularly important during pregnancy because vaginal dismicrobism is one of the most important mechanisms for preterm birth and perinatal complications. In the present study, we characterized the impact of a dietary supplementation with the probiotic VSL\#3, a mixture of Lactobacillus, Bifidobacterium and Streptococcus strains, on the vaginal microbiota and immunological profiles of healthy women during late pregnancy.

Results: An association between the oral intake of the probiotic VSL\#3 and changes in the composition of the vaginal microbiota of pregnant women was revealed by PCR-DGGE population profiling. Despite no significant changes were found in the amounts of the principal vaginal bacterial populations in women administered with VSL\#3, qPCR results suggested a potential role of the probiotic product in counteracting the decrease of Bifidobacterium and the increase of Atopobium, that occurred in control women during late pregnancy. The modulation of the vaginal microbiota was associated with significant changes in some vaginal cytokines. In particular, the decrease of the anti-inflammatory cytokines IL-4 and IL-10 was observed only in control women but not in women supplemented with VSL\#3. In addition, the probiotic consumption induced the decrease of the pro-inflammatory chemokine Eotaxin, suggesting a potential anti-inflammatory effect on the vaginal immunity.
\end{abstract}

Conclusion: Dietary supplementation with the probiotic VSL\#3 during the last trimester of pregnancy was associated to a modulation of the vaginal microbiota and cytokine secretion, with potential implications in preventing preterm birth.

Trial registration: ClinicalTrials.gov NCT01367470

\section{Background}

The vaginal microbiota of healthy women consists of a wide variety of anaerobic and aerobic bacterial genera and species dominated by the facultative, microaerophilic anaerobic genus Lactobacillus [1]. The activity of lactobacilli helps to maintain the natural healthy balance of the vaginal microbiota. This role is particularly important during pregnancy because abnormalities in vaginal communities, such as bacterial vaginosis (BV) and

\footnotetext{
*Correspondence: b.vitali@unibo.it

'Department of Pharmaceutical Sciences, University of Bologna, Bologna, Italy

Full list of author information is available at the end of the article
}

aerobic vaginitis (AV), have been claimed as important mechanisms responsible for preterm birth and perinatal complications [2].

The association of lower genital tract infection with an increased risk of preterm delivery and preterm rupture of the fetal membranes has recently attracted great interest in the pathogenesis of such infection-related mechanisms [3,4]. Earlier studies showed an increased rate of prematurity in women with $\mathrm{BV}$, an alteration of the endogenous vaginal microbiota associated with decreased levels of hydrogen peroxide-producing Lactobacillus species [4-6]. The mechanisms linking BV with preterm delivery have not been fully identified, but local

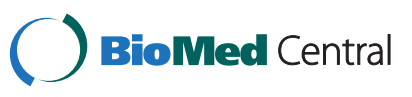


immune response is hypothesized to be crucial. Despite the notion that $\mathrm{BV}$ is a non-inflammatory condition, evidence exists that demonstrates altered levels of certain pro-inflammatory cytokines in women with BV $[7,8]$.

Parturition is characterized by cervical ripening and myometrial maturation with subsequent uterine contractions leading to cervical dilatation and birth [9]. The process of labor displays many of the hallmarks of inflammation. Acute inflammatory features, such as increased influx of leucocytes and elevated expression of pro-inflammatory cytokines, have been observed in cervical tissues and fetal membranes during both term and preterm labor [10-12].

A potentially novel way to protect against infectionmediated preterm birth is to use probiotic bacteria, especially lactobacilli. Probiotics, defined as "live microorganisms which, when administered in adequate amounts, confer a health benefit on the host" [13], are being studied for their ability to replenish vaginal lactobacilli and modulate immunity [14-16]. In addition, administration of probiotics to the mother during pregnancy and breast-feeding has been described by some studies as a safe and effective mode of enhancing the immunoprotective potential of the breast milk and preventing atopic eczema in the infant $[17,18]$.

In recent years, culture-independent techniques based on the analysis of rRNA gene sequences have been developed, providing powerful tools to reveal the phylogenetic diversity of the microorganisms found within vaginal microbiota and to understand community dynamics [19-24]. In particular, PCR-denaturing gradient gel electrophoresis (PCR-DGGE) has been successfully used to identify the bacterial composition of different ecological niches, including the vaginal microbiota $[22,25,26]$. Realtime PCR is a powerful technique for the quantitative analysis of specific microbial populations belonging to complex ecosystems $[22,27,28]$. Specific primers can be used to focus the quantitative analysis on a particular genus, species or strain of interest.

Several bacterial species are known to colonize both the gastrointestinal and the reproductive tract, and the rectum has been suggested to play an important role as a source or reservoir for organisms that colonize the vagina $[15,29]$. On this basis, the aim of the present study was to evaluate the impact of a dietary supplementation with the probiotic product VSL\#3, a mixture of Lactobacillus, Bifidobacterium and Streptococcus strains, on the vaginal microbiota and immunological profiles of asymptomatic healthy women during late pregnancy. The dynamics of the vaginal bacterial communities prior and after probiotic ingestion were assessed by PCR-DGGE and real-time PCR, while the modulation of the cytokine secretion in vaginal fluids was measured by Luminex ${ }^{\circledR}$ Immunoassay. Although previous studies demonstrated the therapeutic efficacy of VSL\#3 in the management of gastrointestinal disorders, especially inflammatory bowel disease [30], as well as the ability of the VSL\#3 strains to colonize the gut environment [31] and to modulate the immune response of the colonic mucosa [32], this is the first study that investigates the indirect effects of this probiotic formula on the vaginal microbiota.

\section{Results}

\section{Bacterial population profiling with PCR-DGGE}

PCR-DGGE analysis with universal primers for bacteria (HDA1-GC/HDA2) was used to investigate: (i) the stability of the predominant vaginal bacterial communities over a period of 4 weeks in the last trimester of pregnancy, from the $33^{\text {rd }}$ (W33) to the $37^{\text {th }}$ (W37) week of gestation, and (ii) the influence of the oral consumption of the probiotic VSL\#3 from W33 to W37 on the predominant vaginal microbiota (Figure 1).

DGGE band profiles displayed a relatively low complexity for both probiotic (P) and control (C) groups, as assessed by the richness index. Mean values of the richness index were 6.6 at both W33 and W37 for C group and shifted from 8.4 (W33) to 7.4 (W37) for P group without significant variations between W33 and W37.

Pearson correlation was used to calculate the similarity index (SI) between DGGE patterns related to the time points W33 and W37 for each pregnant woman (Table 1). The SI median values of $\mathrm{P}$ group and $\mathrm{C}$ group were $73 \%$ and $79 \%$, respectively. In particular, 3 women belonging to P group (N. 2, 9 and 10) and only one woman belonging to $C$ group (N. 24) showed SI values lower that $50 \%$. For each woman, significant differences between DGGE profiles related to W33 and W37 were searched by Wilcoxon Signed Rank Test. No significant variations were detected between W33 and W37 in control women. Significant differences $(P<0.05)$ were found for $5 / 15(33 \%)$ women belonging to $\mathrm{P}$ group $(\mathrm{N} .4,5,9,10,11)$. Interestingly, women N. 9 and 10 were the same presenting SIs $<50 \%$. These data suggested a potential role of the probiotic formula in modulating the vaginal bacterial communities. The peak heights of the DGGE densitometric curves were analyzed using the Wilcoxon Signed Rank Test in order to search for significant differences in single species abundances between W33 and W37. No significant changes in species abundance were found for both $\mathrm{P}$ and $\mathrm{C}$ groups, even in women N. 4, 5, 9, 10, 11.

Cluster analysis showed that the DGGE profiles related to the time points W33 and W37 clustered together for all the control women, except for the woman N. 24 (Figure 1). Four supplemented women (N. 2, 9, 10 and 15) showed W33 and W37 DGGE profiles not closely related. However, the DGGE patterns of the majority of the women administered with VSL\#3 grouped according to the subject and not to the time point, revealing that 


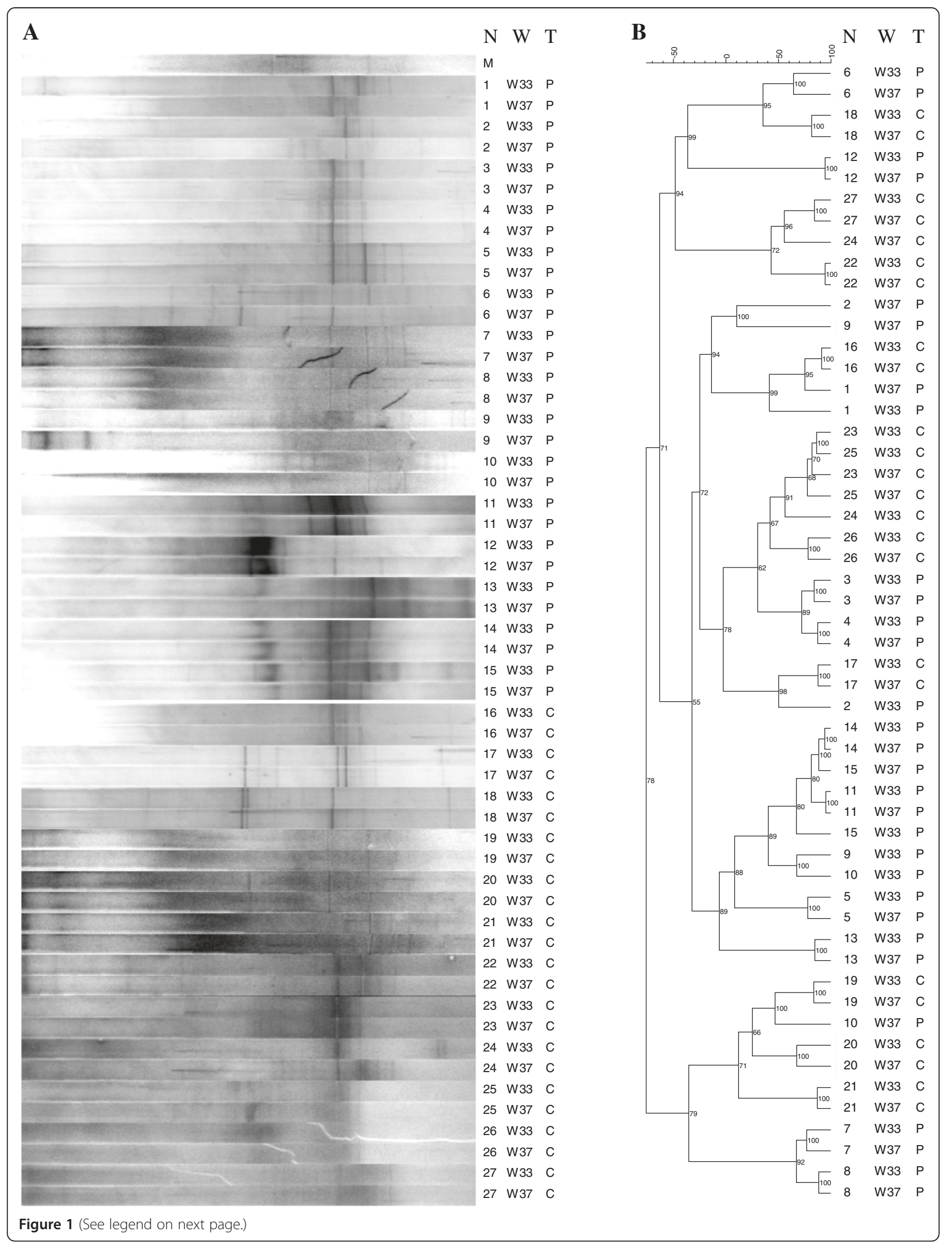


(See figure on previous page.)

Figure 1 PCR-DGGE analysis with universal primers for bacteria. Analysis was conducted on the vaginal samples collected at $33^{\text {rd }}$ (W33) and $37^{\text {th }}$ (W37) week of gestation from 15 women supplemented with the probiotic VSL\#3 [(P) N. 1-15] and 12 control women [(C) N. 16-27]. N: woman number; W: week of gestation; T: type of supplementation. (A) PCR-DGGE fingerprints. M, external reference marker. (B) Dendrogram of the DGGE profiles shown in panel A. Pearson correlation was used to calculate the similarity in DGGE profiles.

the inter-individual variability was higher than the variability induced by the probiotic supplementation.

Because of the importance of lactobacilli in the establishment of a healthy vaginal environment [2], DGGE analysis with Lactobacillus-specific primer set (Lac1/ Lac2-GC) was also carried out. This analysis allowed us to investigate the variations in lactobacilli population occurring physiologically from W33 and W37 and potentially associated with the VSL\#3 intake (Figure 2).

\section{Table 1 Similarity index (SI) of DGGE profiles related to W33 and W37 obtained with universal (HDA1/HDA2) and} Lactobacillus-specific (Lac1/Lac2) primers

\begin{tabular}{|c|c|c|}
\hline Woman $\mathrm{N}$ & HDA1-GC/HDA2 SI (\%) & Lac1/Lac2-GC SI (\%) \\
\hline \multicolumn{3}{|l|}{ Probiotic (P) } \\
\hline 1 & 55.2 & 21.6 \\
\hline 2 & 28.4 & 62.0 \\
\hline 3 & 84.0 & 84.0 \\
\hline 4 & 87.7 & 84.1 \\
\hline 5 & 78.0 & 87.8 \\
\hline 6 & 64.5 & 68.1 \\
\hline 7 & 77.2 & 85.6 \\
\hline 8 & 88.5 & 95.5 \\
\hline 9 & 37.5 & 86.2 \\
\hline 10 & 41.3 & 91.9 \\
\hline 11 & 95.3 & 96.6 \\
\hline 12 & 94.5 & 93.3 \\
\hline 13 & 84.7 & 96.9 \\
\hline 14 & 94.3 & 94.3 \\
\hline 15 & 81.1 & 44.5 \\
\hline \multicolumn{3}{|l|}{ Control (C) } \\
\hline 16 & 91.2 & 90.9 \\
\hline 17 & 87.8 & 93.7 \\
\hline 18 & 81.6 & 76.9 \\
\hline 19 & 83.7 & 91.5 \\
\hline 20 & 67.7 & 81.3 \\
\hline 21 & 87.1 & 94.3 \\
\hline 22 & 94.6 & 74.4 \\
\hline 23 & 85.3 & 74.1 \\
\hline 24 & 25.4 & 46.0 \\
\hline 25 & 84.7 & 84.2 \\
\hline 26 & 78.3 & 68.1 \\
\hline 27 & 84.5 & 86.3 \\
\hline
\end{tabular}

Richness indexes ranged from 5.7 (W33) to 5.4 (W37) for P group and from 6.3 (W33) to 6.8 (W37) for C group. Mean values of SI were $79 \%$ and $80 \%$ for P and C groups, respectively (Table 1). Only 2 women included in $\mathrm{P}$ group showed SIs < 50\% (N. 1 and 15). Wilcoxon Signed Rank Test highlighted significant differences between DGGE profiles related to W33 and W37 for women N. 7 and 10, accounting for $13 \%$ of women included in $\mathrm{P}$ group. Comparing this percentage with the $33 \%$ obtained by DGGE analysis with HDA1-GC/HDA2 primer set, the probiotic intake seemed to have a more extended impact on total bacteria than lactobacilli. Notably, only for woman N. 10, significant differences were found between W33- and W37-related DGGE patterns for both HDA1-GC/HDA2 and Lac1/Lac2-GC primer sets.

The peak height analysis by Wilcoxon Signed Rank Test allowed us to identify a band, denominated L16 (Figure 2), which significantly changed after probiotic supplementation. Sequencing of the DNA extracted from this band revealed $100 \%$ homology with $L$. helveticus strains. The nucleotide sequence of this DGGE fragment was deposited in DDBJ Nucleotide Sequence Database under the accession number AB571603. L. helveticus was found to be a representative species within lactobacilli population since it was detected in 9 women supplemented with VSL\#3 and 2 control women, corresponding to a frequency of occurrence of $40.7 \%$. Notably, a general decrease in the intensity of L. helveticus band was observed in $\mathrm{P}$ group while no variations were appreciable in $\mathrm{C}$ group.

Cluster analysis showed that Lactobacillus-specific DGGE profiles related to the time points W33 and W37 were closely related for all control women and for the majority of women administered with VSL\#3, except for the subjects N. 1 and 15 (Figure 2).

\section{Quantitative variations of vaginal bacterial populations}

Quantitative real-time PCR (qPCR) was performed to analyze changes in concentration of Lactobacillus, Bifidobacterium and Streptococcus thermophilus, that were included in the probiotic VSL\#3, and Gardnerella vaginalis, Atopobium, Prevotella and Veillonella, that are important BV-related genera and species [22,28]. qPCR efficiency for all assays was between $90 \%$ and $110 \%$ and correlation coefficients for genomic DNA standards were $>0.99$. The sensitivity of qPCR assays was $9.1 \times$ $10^{-3}, 1.5 \times 10^{-4}, 3.7 \times 10^{-4}, 1.7 \times 10^{-1}, 1.4 \times 10^{-2}, 4.9$ 


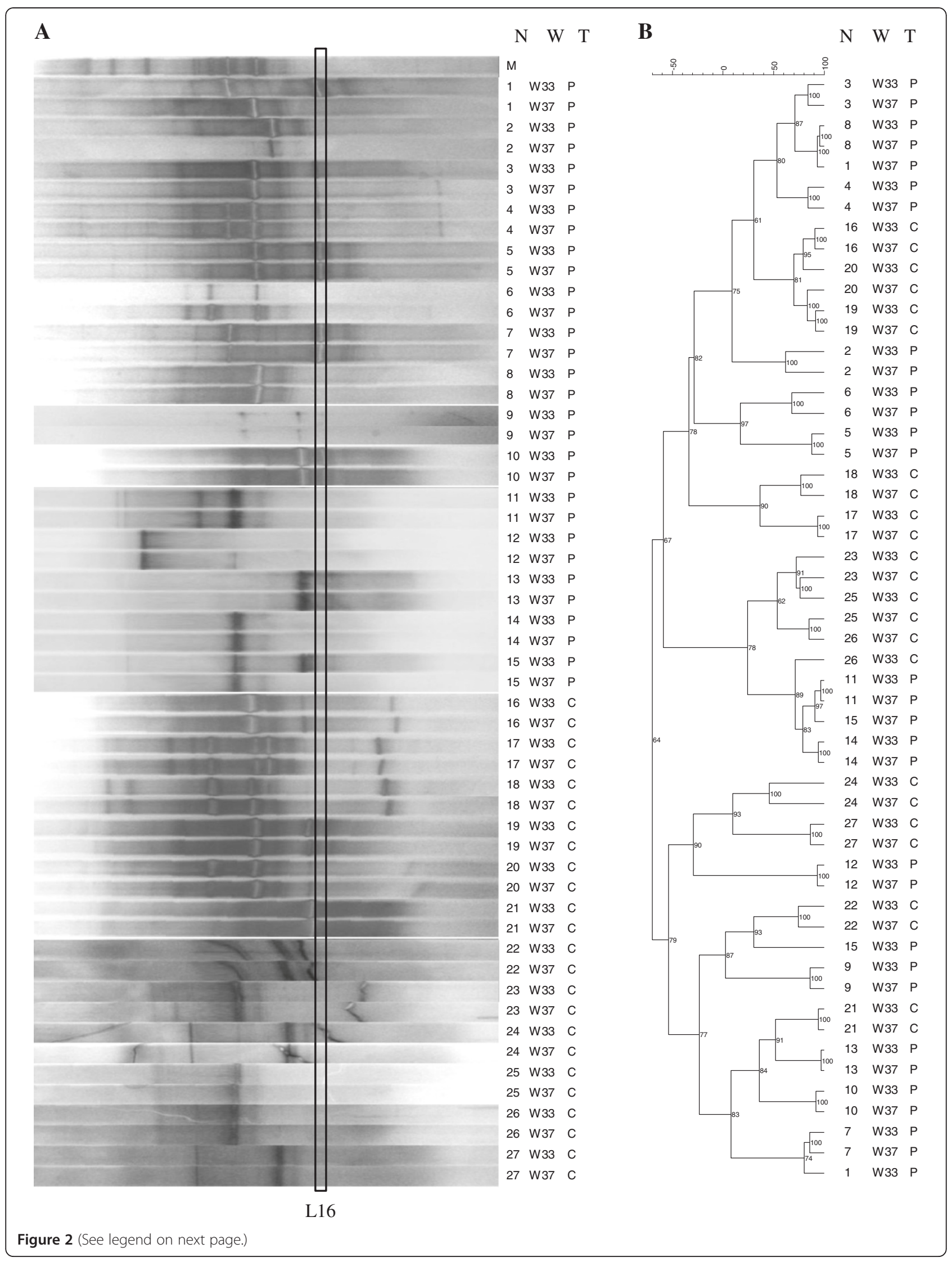


(See figure on previous page.)

Figure 2 PCR-DGGE analysis with Lactobacillus-specific primers. Analysis was conducted on the vaginal samples collected at $33^{\text {rd }}$ (W33) and $37^{\text {th }}$ (W37) week of gestation from 15 women supplemented with the probiotic VSL\#3 [(P) N. 1-15] and 12 control women [(C) N. 16-27]. N: woman number; W: week of gestation; T: type of supplementation. (A) PCR-DGGE fingerprints. M, external reference marker. Band L16 corresponds to L. helveticus (GenBank accession number: AB571603) (B) Dendrogram of the DGGE profiles shown in panel A. Pearson correlation was used to calculate the similarity in DGGE profiles.

$\times 10^{-4}, 3.3 \times 10^{-1} \mathrm{ng}$ of target DNA for Lactobacillus, Bifidobacterium, S. thermophilus, G. vaginalis, Atopobium, Prevotella and Veillonella, respectively. All subjects naturally harbored strains belonging to Lactobacillus, Bifidobacterium, Atopobium and Prevotella, as demonstrated by the presence of these genera in the vaginal samples collected at W33. Woman N. 9 (P group) was the only exception lacking lactobacilli at both the baseline and after one-month intake of VSL\#3 (Table 2). G. vaginalis was found in two women belonging to C group (N. 18 and 20) at both time points at the concentration of $5.5 \times 10^{1} \pm 3.8(\mathrm{~N}$. 18: W33), $7.5 \times 10^{1} \pm 4.6$ (N. 18: W37), $2.2 \times 10^{2} \pm$ $1.8 \times 10^{1}$ (N. 20: W33) and $1.9 \times 10^{2} \pm 3.2 \times 10^{1}(\mathrm{~N}$. 20: W37). S. thermophilus and Veillonella were not detected in any pregnant woman enrolled in this study. Statistical elaboration of qPCR data related to Lactobacillus, Bifidobacterium, Atopobium and Prevotella was performed to search for significant variations of these genera associated with the going on of pregnancy or the probiotic supplementation (Figure 3). No significant changes in the amounts of these bacteria were found between W33 and W37 in both P and C groups. However, in spite of the lack of statistical relevance, a weak modulation was observed for Bifidobacterium and Atopobium. Regarding bifidobacteria (Figure 3B), a physiological tendency to decrease was observed in vaginal samples of control women at the end of the study period (mean value, W33: $4.3 \pm 2.2 \times 10^{-1}$; W37: $2.0 \pm 1.7 \times$ $\left.10^{-1}\right)$. This trend seemed to be counterbalanced in women consuming VSL\#3 since amount of bifidobacteria slightly increased during the supplementation period (mean value, W33: $9.9 \times 10^{-1} \pm 1.6 \times 10^{-1}$; W37: $\left.1.4 \pm 1.2 \times 10^{-1}\right)$. An opposite trend was observed for Atopobium (Figure 3C). This genus increased at W37 (mean value, $9.2 \pm 3.2$ ) compared to W33 (mean value, $7.0 \pm 2.8)$ in $C$ group, while it remained constant after VSL\#3 supplementation (mean value, W33: $1.4 \times 10^{1} \pm$ 3.8; W37: $\left.1.3 \times 10^{1} \pm 5.2\right)$.

\section{Immunological profiles}

The effect of the probiotic intake on the vaginal immune response was evaluated by measuring the levels of 27 cytokines, chemokines and growth factors in the vaginal samples of the pregnant women belonging to $\mathrm{P}$ and $\mathrm{C}$ groups.
Figure 4 shows the cytokines and chemokines whose concentration significantly changed in $\mathrm{P}$ and $\mathrm{C}$ groups during the study period $(P<0.05)$. In group $C$, significant reductions at W37 were found for 5 mediators, 4 cytokines [IL-4 (mean value, W33: $2.8 \times 10^{-2} \pm 1.5 \times$ 10-2 ; W37: $1.3 \times 10^{-2} \pm 6.9 \times 10^{-3}$ ), IL-7 (mean value, W33: $1.2 \times 10^{-1} \pm 8.6 \times 10^{-2}$; W37: $6.1 \times 10^{-2} \pm 3.5 \times$ $10^{-2}$ ), IL-9 (mean value, W33: $1.1 \pm 5.6 \times 10^{-1}$; W37: 3.7 $\times 10^{-1} \pm 1.5 \times 10^{-1}$ ) and IL-10 (mean value, W33: $1.5 \times$ $10^{-1} \pm 1.1 \times 10^{-1}$; W37: $\left.\left.9.4 \times 10^{-2} \pm 5.4 \times 10^{-2}\right)\right]$ and 1 chemokine [RANTES (mean value, W33: $4.3 \pm 2.9$; W37: $\left.1.3 \pm 3.9 \times 10^{-1}\right)$ ]. Both IL-4 and IL-10 are produced by Th2 cells and exert a regulatory role in the immune response. IL-7 and IL-9 are hematopoietic growth factors that control proliferation and homeostasis of a variety of hematopoietic cells. RANTES is a proinflammatory chemokine which attracts monocytes, lymphocytes, basophils and eosinophils in the inflammatory response. In $\mathrm{P}$ group a significant variation was registered only for the chemokine Eotaxin, which decreased after probiotic supplementation (mean value, W33: 5.3 \pm 8.8; W37: $2.0 \pm 2.1$ ). Eotaxin exerts a proinflammatory activity by recruiting eosinophils during allergic responses.

Figure 5 shows women, belonging to $\mathrm{P}$ and $\mathrm{C}$ groups, who registered significant variations in total levels of immune-mediators during the study period $(P<0.05)$. Significant changes were found for women N. 18, 19, 20, $21,23,24,25$ and $27(8 / 12 ; 67 \%)$ of $C$ group and women N. 1, 2, 3, 10, 11 (5/15; 33\%) of P group.

\section{Discussion}

To our knowledge, this is the first study describing the effect of a probiotic mixture, orally consumed during the last trimester of pregnancy, on the vaginal microbiota and immune response. Although several healthpromoting activities of probiotics have been described in relation to the gut homeostasis $[16,32]$, less information is available regarding the interactions between orally administered probiotic bacteria and the vaginal microbial habitat.

The first step in ascertaining the influence of the dietary supplementation with the probiotic VSL\#3 on the vaginal microbiota of pregnant women was the characterization of vaginal bacterial communities by using an integrated approach based on PCR-DGGE and qPCR. 
Table 2 qPCR data of Lactobacillus, Bifidobacterium, Atopobium and Prevotella

\begin{tabular}{|c|c|c|c|c|c|}
\hline \multirow[b]{2}{*}{ Woman N. } & \multirow[b]{2}{*}{ Time point } & \multicolumn{4}{|c|}{ ng of target DNA/ $\mu$ g vaginal genomic DNA (mean \pm SD) } \\
\hline & & Lactobacillus & Bifidobacterium & Atopobium & Prevotella \\
\hline \multicolumn{6}{|l|}{ Probiotic (P) } \\
\hline \multirow[t]{2}{*}{1} & W33 & $2.4 \times 10^{1} \pm 1.1$ & $1.9 \times 10^{-2} \pm 7.4 \times 10^{-3}$ & $3.6 \pm 1.5$ & $2.1 \times 10^{-2} \pm 1.0 \times 10^{-2}$ \\
\hline & W37 & $3.0 \times 10^{1} \pm 3.1$ & $3.1 \times 10^{-2} \pm 2.7 \times 10^{-4}$ & $1.3 \times 10^{1} \pm 6.8$ & $9.1 \times 10^{-2} \pm 1.6 \times 10^{-2}$ \\
\hline \multirow[t]{2}{*}{2} & W33 & $9.6 \pm 8.7 \times 10^{-1}$ & $3.1 \times 10^{-2} \pm 8.8 \times 10^{-3}$ & $5.4 \times 10^{1} \pm 7.4$ & $1.4 \times 10^{-1} \pm 4.8 \times 10^{-2}$ \\
\hline & W37 & $5.9 \times 10^{-1} \pm 4.9 \times 10^{-2}$ & $2.4 \times 10^{-2} \pm 1.2 \times 10^{-2}$ & $2.4 \times 10^{1} \pm 1.9 \times 10^{1}$ & $1.1 \times 10^{-1} \pm 1.1 \times 10^{-2}$ \\
\hline \multirow[t]{2}{*}{3} & W33 & $2.4 \times 10^{1} \pm 2.9$ & $2.4 \times 10^{-2} \pm 4.2 \times 10^{-3}$ & $1.1 \times 10^{1} \pm 6.0$ & $1.1 \times 10^{-1} \pm 7.7 \times 10^{-3}$ \\
\hline & W37 & $2.2 \times 10^{1} \pm 2.4$ & $3.0 \times 10^{-2} \pm 2.4 \times 10^{-3}$ & $4.0 \pm 2.3$ & $5.2 \times 10^{-2} \pm 8.2 \times 10^{-3}$ \\
\hline \multirow[t]{2}{*}{4} & W33 & $2.2 \times 10^{1} \pm 2.0$ & $6.8 \times 10^{-2} \pm 8.3 \times 10^{-3}$ & $4.7 \pm 1.9$ & $7.3 \times 10^{-2} \pm 2.9 \times 10^{-2}$ \\
\hline & W37 & $1.5 \times 10^{1} \pm 1.4$ & $2.1 \times 10^{-2} \pm 7.2 \times 10^{-3}$ & $5.2 \pm 2.0$ & $4.6 \times 10^{-2} \pm 9.5 \times 10^{-3}$ \\
\hline \multirow[t]{2}{*}{5} & W33 & $2.5 \times 10^{1} \pm 4.5$ & $2.1 \times 10^{-2} \pm 3.4 \times 10^{-3}$ & $1.2 \times 10^{1} \pm 3.0$ & $9.3 \times 10^{-2} \pm 8.3 \times 10^{-3}$ \\
\hline & W37 & $2.2 \times 10^{1} \pm 4.5$ & $1.4 \times 10^{-2} \pm 3.2 \times 10^{-3}$ & $1.5 \times 10^{1} \pm 1.9$ & $3.0 \times 10^{-2} \pm 1.1 \times 10^{-2}$ \\
\hline \multirow[t]{2}{*}{6} & W33 & $1.1 \times 10^{-1} \pm 3.4 \times 10^{-3}$ & $7.1 \times 10^{-2} \pm 7.1 \times 10^{-3}$ & $1.0 \times 10^{1} \pm 4.1$ & $1.2 \times 10^{-1} \pm 1.3 \times 10^{-2}$ \\
\hline & W37 & $2.2 \pm 6.0 \times 10^{-1}$ & $2.1 \pm 1.7 \times 10^{-1}$ & $2.4 \times 10^{1} \pm 1.0 \times 10^{1}$ & $1.5 \times 10^{-1} \pm 1.2 \times 10^{-2}$ \\
\hline \multirow[t]{2}{*}{7} & W33 & $4.1 \times 10^{1} \pm 8.5$ & $3.7 \times 10^{-2} \pm 5.4 \times 10^{-3}$ & $2.9 \times 10^{1} \pm 9.2$ & $1.2 \times 10^{-1} \pm 2.1 \times 10^{-2}$ \\
\hline & W37 & $2.0 \times 10^{1} \pm 2.6$ & $1.7 \times 10^{-2} \pm 4.4 \times 10^{-3}$ & $2.6 \times 10^{1} \pm 7.7$ & $1.1 \times 10^{-1} \pm 1.1 \times 10^{-3}$ \\
\hline \multirow[t]{2}{*}{8} & W33 & $1.0 \times 10^{1} \pm 1.7 \times 10^{-1}$ & $1.3 \times 10^{-2} \pm 1.9 \times 10^{-3}$ & $5.5 \pm 1.2$ & $4.2 \times 10^{-2} \pm 1.9 \times 10^{-2}$ \\
\hline & W37 & $2.1 \times 10^{1} \pm 2.0$ & $1.5 \times 10^{-2} \pm 2.6 \times 10^{-3}$ & $1.6 \times 10^{1} \pm 6.6$ & $5.1 \times 10^{-2} \pm 3.3 \times 10^{-3}$ \\
\hline \multirow[t]{2}{*}{9} & W33 & $0.0 \pm 0.0$ & $7.1 \times 10^{-3} \pm 2.8 \times 10^{-5}$ & $1.8 \times 10^{1} \pm 7.1$ & $6.7 \times 10^{-2} \pm 1.5 \times 10^{-2}$ \\
\hline & W37 & $0.0 \pm 0.0$ & $1.1 \times 10^{1} \pm 1.0$ & $1.5 \times 10^{1} \pm 6.8$ & $2.3 \times 10^{-1} \pm 8.0 \times 10^{-2}$ \\
\hline \multirow[t]{2}{*}{10} & W33 & $6.7 \pm 6.1 \times 10^{-1}$ & $2.0 \times 10^{-2} \pm 4.8 \times 10^{-3}$ & $1.4 \times 10^{1} \pm 4.3$ & $8.6 \times 10^{-2} \pm 2.0 \times 10^{-2}$ \\
\hline & W37 & $1.1 \times 10^{1} \pm 1.4$ & $2.3 \times 10^{-2} \pm 1.5 \times 10^{-2}$ & $1.7 \times 10^{1} \pm 9.7$ & $8.0 \times 10^{-2} \pm 2.9 \times 10^{-2}$ \\
\hline \multirow[t]{2}{*}{11} & W33 & $2.7 \times 10^{1} \pm 1.7$ & $2.9 \times 10^{-3} \pm 1.7 \times 10^{-3}$ & $2.3 \pm 1.8$ & $3.2 \times 10^{-2} \pm 3.3 \times 10^{-3}$ \\
\hline & W37 & $3.0 \times 10^{1} \pm 5.6$ & $1.3 \times 10^{-2} \pm 8.5 \times 10^{-3}$ & $1.3 \pm 7.5 \times 10^{-1}$ & $3.6 \times 10^{-2} \pm 1.3 \times 10^{-2}$ \\
\hline \multirow[t]{2}{*}{12} & W33 & $2.2 \pm 5.6 \times 10^{-1}$ & $1.5 \times 10^{1} \pm 2.3$ & $1.4 \times 10^{1} \pm 2.9$ & $2.2 \times 10^{-1} \pm 2.1 \times 10^{-2}$ \\
\hline & W37 & $2.0 \pm 3.1 \times 10^{-1}$ & $8.7 \pm 5.6 \times 10^{-1}$ & $1.2 \times 10^{1} \pm 2.3$ & $1.0 \times 10^{-1} \pm 1.8 \times 10^{-2}$ \\
\hline \multirow[t]{2}{*}{13} & W33 & $3.7 \times 10^{1} \pm 5.4$ & $3.0 \times 10^{-2} \pm 4.5 \times 10^{-3}$ & $7.0 \pm 2.6 \times 10^{-1}$ & $2.7 \times 10^{-2} \pm 5.0 \times 10^{-4}$ \\
\hline & W37 & $6.6 \times 10^{1} \pm 5.9$ & $1.1 \times 10^{-2} \pm 2.2 \times 10^{-3}$ & $6.8 \pm 6.6 \times 10^{-1}$ & $5.7 \times 10^{-2} \pm 2.0 \times 10^{-3}$ \\
\hline \multirow[t]{2}{*}{14} & W33 & $2.2 \times 10^{1} \pm 8.5$ & $1.7 \times 10^{-2} \pm 4.9 \times 10^{-3}$ & $9.0 \pm 4.4 \times 10^{-1}$ & $6.7 \times 10^{-2} \pm 6.6 \times 10^{-3}$ \\
\hline & W37 & $1.6 \times 10^{1} \pm 4.9$ & $2.8 \times 10^{-2} \pm 4.7 \times 10^{-3}$ & $1.1 \times 10^{1} \pm 1.1$ & $1.1 \times 10^{-1} \pm 1.8 \times 10^{-3}$ \\
\hline \multirow[t]{2}{*}{15} & W33 & $2.2 \times 10^{1} \pm 7.1$ & $1.4 \times 10^{-2} \pm 7.1 \times 10^{-3}$ & $1.8 \times 10^{1} \pm 5.6$ & $1.1 \times 10^{-1} \pm 1.4 \times 10^{-2}$ \\
\hline & W37 & $2.8 \times 10^{1} \pm 3.4$ & $4.7 \times 10^{-3} \pm 2.3 \times 10^{-3}$ & $1.1 \times 10^{1} \pm 2.4 \times 10^{-1}$ & $7.4 \times 10^{-2} \pm 2.4 \times 10^{-3}$ \\
\hline \multicolumn{6}{|l|}{ Control (C) } \\
\hline \multirow[t]{2}{*}{16} & W33 & $5.4 \times 10^{1} \pm 4.0$ & $2.1 \times 10^{-2} \pm 5.6 \times 10^{-3}$ & $1.1 \times 10^{1} \pm 4.6$ & $6.8 \times 10^{-2} \pm 1.1 \times 10^{-2}$ \\
\hline & W37 & $2.0 \times 10^{1} \pm 1.7$ & $2.0 \times 10^{-2} \pm 7.4 \times 10^{-3}$ & $1.4 \times 10^{1} \pm 5.0$ & $5.6 \times 10^{-2} \pm 5.4 \times 10^{-3}$ \\
\hline \multirow[t]{2}{*}{17} & W33 & $5.5 \pm 5.3 \times 10^{-1}$ & $6.0 \pm 1.6 \times 10^{-1}$ & $1.2 \times 10^{1} \pm 4.3$ & $5.9 \times 10^{-2} \pm 2.3 \times 10^{-2}$ \\
\hline & W37 & $1.5 \times 10^{1} \pm 2.9$ & $9.3 \pm 5.3 \times 10^{-1}$ & $1.9 \times 10^{1} \pm 8.7$ & $5.4 \times 10^{-2} \pm 1.0 \times 10^{-2}$ \\
\hline 18 & W33 & $2.6 \pm 1.6 \times 10^{-1}$ & $1.8 \pm 3.5 \times 10^{-2}$ & $1.3 \times 10^{1} \pm 5.5$ & $8.8 \times 10^{-2} \pm 1.7 \times 10^{-2}$ \\
\hline & W37 & $1.2 \times 10^{1} \pm 2.0$ & $2.9 \pm 7.5 \times 10^{-2}$ & $3.3 \times 10^{1} \pm 4.4$ & $4.5 \times 10^{-2} \pm 2.8 \times 10^{-3}$ \\
\hline 19 & W33 & $7.6 \times 10^{1} \pm 3.3 \times 10^{-1}$ & $1.2 \pm 7.9 \times 10^{-3}$ & $1.3 \times 10^{1} \pm 3.6$ & $1.9 \times 10^{-1} \pm 3.2 \times 10^{-3}$ \\
\hline & W37 & $2.7 \times 10^{1} \pm 3.8$ & $2.7 \times 10^{-2} \pm 4.7 \times 10^{-3}$ & $8.2 \pm 4.6$ & $1.1 \times 10^{-1} \pm 2.6 \times 10^{-2}$ \\
\hline 20 & W33 & $1.6 \times 10^{1} \pm 1.4$ & $1.1 \times 10^{1} \pm 1.2$ & $1.2 \times 10^{1} \pm 5.5$ & $8.6 \times 10^{-2} \pm 1.5 \times 10^{-2}$ \\
\hline & W37 & $1.0 \times 10^{1} \pm 6.4 \times 10^{-2}$ & $1.1 \times 10^{1} \pm 1.4$ & $1.2 \times 10^{1} \pm 4.7$ & $1.1 \times 10^{-1} \pm 3.1 \times 10^{-2}$ \\
\hline 21 & W33 & $5.6 \times 10^{1} \pm 8.3$ & $1.7 \times 10^{-2} \pm 1.7 \times 10^{-3}$ & $2.1 \times 10^{1} \pm 1.0 \times 10^{1}$ & $1.3 \times 10^{-1} \pm 2.0 \times 10^{-2}$ \\
\hline & W37 & $6.4 \times 10^{1} \pm 1.5$ & $3.3 \times 10^{-2} \pm 8.7 \times 10^{-3}$ & $2.2 \times 10^{1} \pm 1.0 \times 10^{1}$ & $1.2 \times 10^{-1} \pm 2.4 \times 10^{-2}$ \\
\hline 22 & W33 & $4.3 \times 10^{1} \pm 2.0$ & $1.2 \times 10^{-1} \pm 2.8 \times 10^{-2}$ & $2.3 \times 10^{-1} \pm 1.5 \times 10^{-2}$ & $0.0 \pm 0.0$ \\
\hline & W37 & $6.8 \times 10^{1} \pm 5.1$ & $2.7 \times 10^{-2} \pm 6.6 \times 10^{-3}$ & $1.9 \times 10^{-1} \pm 2.0 \times 10^{-2}$ & $0.0 \pm 0.0$ \\
\hline
\end{tabular}


Table 2 qPCR data of Lactobacillus, Bifidobacterium, Atopobium and Prevotella (Continued)

\begin{tabular}{llcccc}
\hline 23 & W33 & $2.6 \times 10^{1} \pm 5.6$ & $2.3 \times 10^{-1} \pm 3.6 \times 10^{-2}$ & $0.0 \pm 0.0$ & $0.0 \pm 0.0$ \\
\hline 24 & W37 & $6.3 \times 10^{1} \pm 2.0$ & $8.2 \times 10^{-3} \pm 1.9 \times 10^{-3}$ & $1.6 \times 10^{-1} \pm 2.9 \times 10^{-2}$ & $5.3 \times 10^{-1} \pm 1.8 \times 10^{-1}$ \\
\hline W33 & $1.2 \times 10^{1} \pm 1.0$ & $2.7 \times 10^{1} \pm 2.1 \times 10^{-1}$ & $1.8 \pm 1.5 \times 10^{-1}$ & $6.8 \times 10^{-1} \pm 3.4 \times 10^{-2}$ \\
\hline 25 & W37 & $7.5 \times 10^{1} \pm 3.8$ & $9.7 \times 10^{-3} \pm 3.7 \times 10^{-3}$ & $3.7 \times 10^{-1} \pm 3.4 \times 10^{-2}$ & $0.0 \pm 0.0$ \\
\hline W33 & $6.5 \times 10^{1} \pm 1.0 \times 10^{1}$ & $3.0 \times 10^{-2} \pm 1.0 \times 10^{-2}$ & $7.5 \times 10^{-2} \pm 7.5 \times 10^{-3}$ & $0.0 \pm 0.0$ \\
\hline W37 & $6.6 \times 10^{1} \pm 7.1$ & $9.1 \times 10^{-3} \pm 5.1 \times 10^{-4}$ & $2.5 \times 10^{-1} \pm 2.7 \times 10^{-2}$ & $0.0 \pm 0.0$ \\
\hline 27 & W33 & $8.5 \times 10^{1} \pm 6.3$ & $4.4 \pm 9.3 \times 10^{-1}$ & $3.2 \times 10^{-1} \pm 3.9 \times 10^{-2}$ & $0.0 \pm 0.0$ \\
\hline & W37 & $5.4 \times 10^{1} \pm 4.5$ & $2.0 \times 10^{-2} \pm 6.1 \times 10^{-4}$ & $3.6 \times 10^{-1} \pm 4.2 \times 10^{-2}$ & $0.0 \pm 0.0$ \\
\hline
\end{tabular}

DGGE population profiling, conducted with universal primers for bacteria and Lactobacillus-specific primers, allowed us to investigate the variations of the predominant vaginal bacterial communities and Lactobacillus species occurring both physiologically in the last trimester of pregnancy and potentially associated with VSL\#3 intake. The influence of the probiotic intake in modulating the predominant bacterial populations and Lactobacillus species could be hypothesized since significant differences between DGGE profiles at W33 and W37 were found only in women belonging to $\mathrm{P}$ group. Notably, the lower percentage of women belonging to $\mathrm{P}$ group who displayed significant differences in Lactobacillus-specific DGGE profiles between W33 and W37, compared to the universal bacterial DGGE patterns, suggested a major stability of lactobacilli population and a more extended impact of the probiotic VSL\#3 on total bacteria than lactobacilli. However, no significant changes in single species abundances were found between W33- and W37-related universal DGGE profiles. Differently, the statistical analysis of the peak heights of the Lactobacillus-specific DGGE densitometric curves allowed us to identify a band, corresponding to L. helveticus, which significantly decreased after probiotic supplementation. Strains belonging to L. helveticus are used as starter cultures in the manufacturing of a variety of fermented dairy products, to modulate flavor. The presence of $L$. helveticus in vagina, likely due to the migration from the gut, can be related to a diet rich in yogurt and cheese. This work is not the first describing L. helveticus in vaginal samples. Stoyancheva et al. [33] identified this species among several Lactobacillus isolates from vaginal fluids of healthy Bulgarian women in childbearing age by using three different molecular techniques, amplified ribosomal DNA restriction analysis, ribotyping and PCR with species-specific primers. The decrease of L. helveticus observed in our study could be due to a competition between the Lactobacillus strains present in VSL\#3 formula and dairy L. helveticus strains in colonizing vaginal environment.
Cluster analysis showed that universal and Lactobacillusspecific DGGE profiles related to the time points W33 and W37 of the control women were closely related. Also the DGGE patterns of the majority of women administered with VSL\#3 grouped according to the subject and not to the time point, revealing that the interindividual variability was higher than variability induced by the probiotic supplementation.

The hypothesis of a positive action of VSL\#3 on the vaginal microbiota of pregnant women was further supported by qPCR results, which suggested a role of the probiotic product in counteracting the decrease of the health-promoting Bifidobacterium genus and the increase of the BV-related Atopobium genus, that occurred in control women during late pregnancy. Notably, group B Streptococcus, which was found in two women (N.1 and 10) before the probiotic intake, was no longer found after the dietary supplementation (data not shown).

The second step of the present research was the investigation of the vaginal immunological profiles of the pregnant women in order to search for correlations between the VSL\#3 intake and changes in vaginal immune response. Pregnancy has been referred to as a state of relative immune compromise. This notion has been related to both demonstration of depression of certain aspects of cell-mediated immunity and clinical observations of an increased severity of numerous infectious conditions in pregnant women [7]. On the other hand, preterm cervical ripening can be likened to an inflammatory process with cytokines as important mediators [34].

Bioplex immunoassay was used in the present work to measure levels of 27 cytokines, chemokines and growth factors in the vaginal samples of the pregnant women belonging to $\mathrm{P}$ and $\mathrm{C}$ groups. In group $\mathrm{C}$ a significant reduction at W37 was found for IL-4, IL-7, IL-9, IL-10 and RANTES. IL-4 is a key regulator in humoral and adaptive immunity. It has many biological roles, including the stimulation of activated B-cells and T-cell proliferation, and the differentiation of CD4+ T-cells into Th2 


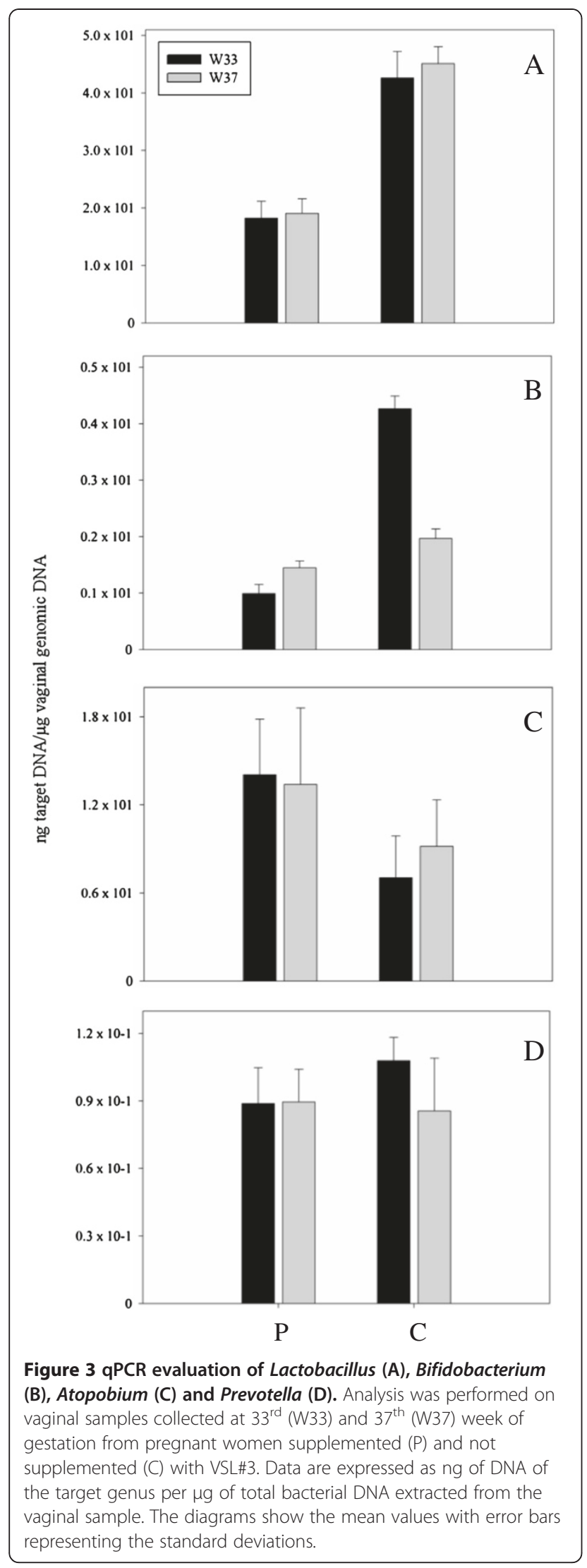

cells. A regulatory role is also exerted by IL-10. In relation to pregnancy, IL-10 decreases the production of pro-inflammatory cytokines, such as IL-8, IL-6, TNF $\alpha$, IL-1 $\beta$ and prostaglandin $E_{2}$ in lipopolysaccharidestimulated fetal membranes $[35,36]$. Both IL-4 and IL10 are produced by Th2 cells. IL-7 and IL-9 are hematopoietic growth factors that act as regulators of cell survival, proliferation and homeostasis of a variety of hematopoietic cells. RANTES is a potent and versatile chemokine, capable of attracting monocytes, lymphocytes, basophils and eosinophils. This cytokine has been implicated in the regulation of the inflammatory response and recruitment of macrophages to the implantation site in early pregnancy [37]. However, no variations in RANTES levels have been associated with preterm cervical ripening and labor [34]. Immunological profiles related to women belonging to $\mathrm{C}$ group indicated that some fluctuations in vaginal immune-

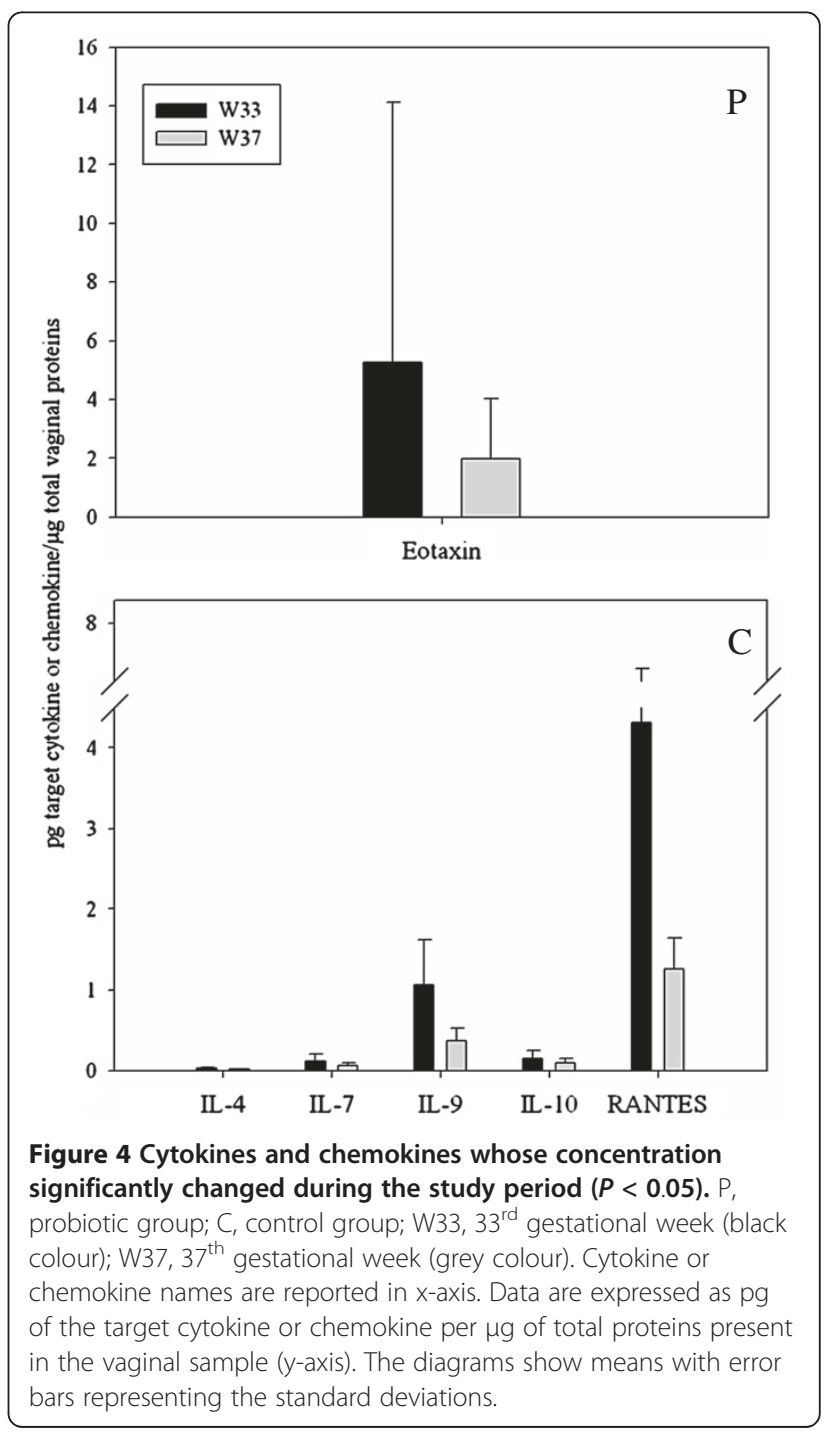




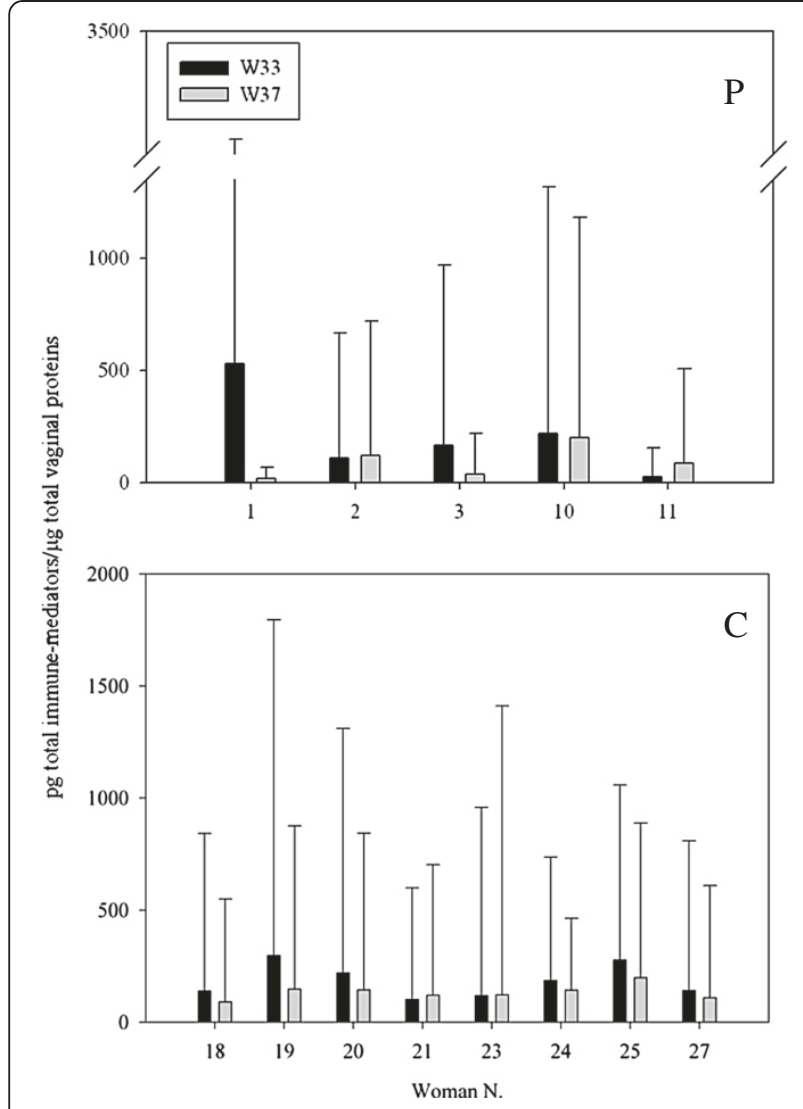

Figure $\mathbf{5}$ Women registering significant variations in total levels of immune-mediators. P, probiotic group; C, control group; W33, $33^{\text {rd }}$ gestational week (black colour); W37, $37^{\text {th }}$ gestational week (grey colour). Identification numbers of women registering significant variations are reported in $\mathrm{x}$-axis. Data are expressed as pg of total immune-mediators per $\mu \mathrm{g}$ of total vaginal proteins ( $y$-axis). The diagrams show means with error bars representing the standard deviations.

modulators occurred physiologically during the last trimester of pregnancy. In particular, it is noteworthy the decrease of IL-10 and IL-4, important regulatory cytokines controlling the inflammatory reaction responsible for uterine contractions and cervical ripening at the labor time [12]. In $\mathrm{P}$ group a significant variation was registered only for the chemokine Eotaxin, which decreased after probiotic supplementation. Eotaxin selectively recruits eosinophils, and for this reason is implicated in allergic responses [38]. By comparing the data related to the two study groups, the following hypotheses could be formulated regarding the possible impact of the probiotic intake on cytokine secretion during late pregnancy: (i) probiotics counteracted the decrease of anti-inflammatory cytokine levels occurring in C group; (ii) probiotics induced the decrease of a proinflammatory cytokine in $\mathrm{P}$ group, showing a global anti-inflammatory effect on the vaginal immunity. In addition, a stabilization effect on the vaginal immunity during late pregnancy could be attributed to the probiotic intake, since the percentage of women with modified amounts of immune-mediators decreased from 67\% to $31 \%$ in relation to the dietary supplementation.

\section{Conclusion}

The impact of the oral intake of the probiotic VSL\#3 on the vaginal microbiota and immune response of pregnant women was investigated by molecular fingerprinting techniques (PCR-DGGE and qPCR) and Luminex ${ }^{\circledR}$ immunoassay. The major findings of this study are the following: (i) VSL\#3 intake seems to be associated with a modulation of the predominant vaginal bacterial communities; (ii) VSL\#3 modulation of Lactobacillus population appears to be related to variations of $L$. helveticus species; (iii) a potential role of the probiotic product in counteracting the physiological decrease of Bifidobacterium and increase of Atopobium could be hypothesized; (iv) the probiotic supplementation can be associated with a global antiinflammatory effect on the vaginal immunity, with potential implications in preventing preterm birth.

\section{Methods}

\section{Study design and sample collection}

A pilot, not randomized, controlled and perspective study was conducted. The study protocol was approved by the ethical committee of the University of Bari, Italy. Written informed consent was obtained from all the participants in the study. A total of 27 healthy pregnant women (21 to 42 years of age; mean, 32) who had no symptoms of vaginal or urinary tract infection were included in the present study (Table 3). None of the subjects had received oral or local antimicrobial therapy within the previous 2 weeks. The recruited subjects were divided into 2 groups: (i) probiotic group [P $(n=15)$ ]; (ii) control group $[\mathrm{C}(\mathrm{n}=12)]$ on the basis of their availability to consume the probiotic product. Women of the P group consumed 1 sachet once/day of VSL\#3 (VSL Pharmaceuticals, Inc.,Towson, MD, USA) for 4 weeks from the $33^{\text {rd }}$ (W33) to the $37^{\text {th }}$ (W37) week of gestation. Women of the $\mathrm{C}$ group did not receive any dietary supplementation. VSL\#3 sachet contains 900 billion viable lyophilized bacteria consisting of 4 strains of Lactobacillus (L. paracasei, L. plantarum, L. acidophilus, $L$. delbrueckii subsp. bulgaricus), 3 strains of Bifidobacterium (B. longum, B. breve, B. infantis) and 1 strain of Streptococcus thermophilus. Mid-vaginal swabs were collected from women of both $\mathrm{P}$ and $\mathrm{C}$ groups at the time points W33 and W37. Samples were placed in $1 \mathrm{ml}$ of sterile saline and stored immediately at $-80^{\circ} \mathrm{C}$ until use.

The individual characteristics (age, type of delivery and gestational age at birth) of women enrolled in the present study are reported in Table 3. Gestational age was determined by utilizing the last menstrual period and earliest ultrasound. 
Table 3 Characterization of the subjects included in the study groups

\begin{tabular}{|c|c|c|c|}
\hline Woman N & Age & Type of delivery ${ }^{1}$ & Gestational age at birth \\
\hline \multicolumn{4}{|c|}{ Probiotic $(n=15)$} \\
\hline 1 & 31 & SD & 39 week +6 days \\
\hline 2 & 32 & $C D$ & 40 week +3 days \\
\hline 3 & 39 & SD & 40 week +1 day \\
\hline 4 & 31 & SD & 40 week +2 days \\
\hline 5 & 33 & SD & 40 week +3 days \\
\hline 6 & 30 & SD & 39 week \\
\hline 7 & 33 & SD & 41 week +3 days \\
\hline 8 & 34 & $C D$ & 39 week \\
\hline 9 & 36 & $C D$ & 38 week +4 days \\
\hline 10 & 38 & SD & 38 week +5 days \\
\hline 11 & 42 & SD & 39 week +4 days \\
\hline 12 & 30 & SD & 39 week \\
\hline 13 & 29 & SD & 40 week +2 days \\
\hline 14 & 33 & $C D$ & 39 week +2 days \\
\hline 15 & 25 & SD & 40 week + 1 day \\
\hline \multicolumn{4}{|c|}{ Control $(n=12)$} \\
\hline 16 & 28 & SD & 40 week +6 days \\
\hline 17 & 33 & SD & 39 week +3 days \\
\hline 18 & 33 & $C D$ & 37 week +4 days \\
\hline 19 & 32 & $C D$ & 41 week +3 days \\
\hline 20 & 34 & SD & 40 week \\
\hline 21 & 21 & SD & 39 week +5 days \\
\hline 22 & 30 & SD & 38 week +6 days \\
\hline 23 & 30 & SD & 40 week +2 days \\
\hline 24 & 34 & $C D$ & 39 week +6 days \\
\hline 25 & 38 & $C D$ & 41 week +1 days \\
\hline 26 & 38 & $C D$ & 38 week +5 days \\
\hline 27 & 30 & SD & 40 week +2 days \\
\hline
\end{tabular}

\section{DNA extraction from vaginal samples}

Frozen vaginal swabs were thawed, mixed by vortex shaker for $1 \mathrm{~min}$ and then removed from the liquid. The liquid was centrifuged at $10,000 \times \mathrm{g}$ for $15 \mathrm{~min}$, and the pellet was washed 3 times in saline at $40^{\circ} \mathrm{C}$. The pellet was resuspended in $180 \mu \mathrm{l}$ of enzymatic lysis buffer $(20 \mathrm{mM}$ Tris$\mathrm{HCl}, \mathrm{pH}$ 8, 2 mM EDTA, 1.2\% Triton X-100, $20 \mathrm{mg} / \mathrm{ml}$ lysozyme) and incubated at $37^{\circ} \mathrm{C}$ for $30 \mathrm{~min}$. Glass beads (200 mg) were added and the sample was mixed by vortexing for $1 \mathrm{~min}$. Total DNA was extracted by using the DNeasy Blood \& Tissue Kit (Qiagen, Hilden, Germany) following the protocol "Pretreatment for Gram-positive bacteria". A slight modification was introduced: a centrifugation step $(8000 \times \mathrm{g}$ for $5 \mathrm{~min})$ was carried out after incubation with proteinase $\mathrm{K}$ to remove glass beads. DNA amounts were quantified by using NanoDrop 1000 (Thermo Scientific, Wilmington, DE).

\section{PCR-DGGE and cluster analysis}

Amplification reactions were performed in a Biometra Thermal Cycler T Gradient (Biometra, Göttingen, Germany). GoTaq Flexi DNA Polymerase (Promega, Madison, WI) was used as thermostable DNA polymerase. The reaction mixture contained $0.5 \mu \mathrm{M}$ of each primer, $200 \mu \mathrm{M}$ of each dNTP, $2 \mathrm{mM} \mathrm{MgCl}_{2}$ solution, 1.25 U of GoTaq Flexi DNA Polymerase, $5 \mu \mathrm{l}$ of Green GoTaq Flexi buffer $5 \mathrm{X}$, and $2 \mu \mathrm{l}$ of the bacterial DNA template (30-40 ng) in a final volume of $25 \mu \mathrm{l}$. The universal primers HDA1-GCclamp and HDA2 for bacteria [39] were used to amplify a conserved region within the 16S rRNA gene. The thermocycle program consisted of the following time and temperature profile: $95^{\circ} \mathrm{C}$ for $5 \mathrm{~min}$; 30 cycles of $95^{\circ} \mathrm{C}$ for $30 \mathrm{~s}, 56^{\circ} \mathrm{C}$ for $30 \mathrm{~s}, 72^{\circ} \mathrm{C}$ for $60 \mathrm{~s}$; and $72^{\circ} \mathrm{C}$ for $8 \mathrm{~min}$. The Lactobacillus genus-specific primers Lac1 and Lac2-GCclamp [40] were used to amplify a specific region of the $16 \mathrm{~S}$ rRNA gene of lactobacilli. The amplification program was $95^{\circ} \mathrm{C}$ for 5 min; 35 cycles of $95^{\circ} \mathrm{C}$ for $30 \mathrm{~s}, 61^{\circ} \mathrm{C}$ for $30 \mathrm{~s}, 72^{\circ} \mathrm{C}$ for $60 \mathrm{~s}$; and $72^{\circ} \mathrm{C}$ for $8 \mathrm{~min}$. A volume of $8 \mu \mathrm{l}$ of PCR samples was loaded on DGGE gels, containing $30-50 \%$ and $25-55 \%$ gradients of urea and formamide for universal bacteria and lactobacilli, respectively. DGGE analysis was performed by using the D-Code Universal Mutation System Apparatus (Bio-Rad, Los Angeles, CA), as previously described [22]. Following electrophoresis, gels were silver stained [41] and scanned using a Molecular Imager Gel Doc XR System (Bio-Rad). DGGE gel images were analyzed using the FPQuest software version 4.5 (BioRad). In order to compensate for gel-to-gel differences and external distortion to electrophoresis, the DGGE patterns were aligned and normalized using an external reference marker. The marker for the DGGE analysis with the universal primers for bacteria contained PCR amplicons from Bacteroides, Coriobacterium, Enterococcus faecalis, Bifidobacterium bifidum, Lactobacillus casei, Acidaminococcus fermentas and Atopobium. The marker for the DGGE analysis with Lactobacillus-specific primers contained PCR amplicons from L. plantarum, L. paracasei, L. brevis, L. gasseri, L. acidophilus and $L$. delbrueckii subsp. bulgaricus. After normalization, bands were defined for each sample using the appropriate densitometric curve. The similarity in the profiles was calculated on the basis of the Pearson correlation coefficient with the Ward clustering algorithm. Cluster analysis of the DGGE patterns was performed using the FPQuest software.

\section{Sequencing of DGGE fragment}

The DNA fragment of interest was excised from the denaturing gel with a sterile scalpel, washed once in $1 \mathrm{X}$ PCR buffer, and incubated in $20 \mu \mathrm{l}$ of the same buffer overnight at $4^{\circ} \mathrm{C}$. Two $\mu$ l of the buffer solution were 
used as a template for PCR reaction. Reamplification of the $16 \mathrm{~S}$ rRNA region was conducted as described above by employing the primers Lac1 and Lac2 (without the GC-clamp). The re-amplified fragment was purified using the Wizard SV Gel and PCR Clean-up system (Promega), and then subjected to automated sequence analysis of both DNA strands with Lac1 and Lac2. BigDye terminators (ABI-PerkinElmer, Foster City, CA) were used with a 377 sequencer (ABI). Sequence identity was determined by comparison with the rRNA gene sequences deposited in GenBank database using BLAST algorithm (www.ncbi.nlm.nih.gov/BLAST).

\section{Quantitative real-time PCR}

Quantitative PCR was performed in a LightCycler instrument (Roche, Mannheim, Germany) and SYBR Green I fluorophore was used to correlate the amount of PCR product with the fluorescence signal. Each DNA sample was amplified with different genus- or speciesspecific primer sets targeted to $16 \mathrm{~S}$ rRNA gene or 16S23S rRNA spacer region: Bact-0011f/Lab-0677r [42] for Lactobacillus, Bif164/Bif662 [43] for Bifidobacterium, Th1/Th2 [44] for Streptococcus thermophilus, F-GV1/RGV3 [45] for Gardnerella vaginalis, c-Atopo-f/c-Atopo-r [46] for Atopobium, g-Prevo-f/g-Prevo-r [47] for Prevotella, VeilloF/VeilloR [48] for Veillonella. Amplifications were carried out in a final volume of $20 \mu \mathrm{l}$ containing $0.5 \mu \mathrm{M}$ of each primer, $4 \mu \mathrm{l}$ of LightCycler-FastStart DNA Master SYBR Green I (Roche) and either $2 \mu \mathrm{l}$ of template or water (no-template control).

The thermal cycling conditions were as follows: an initial denaturation step at $95^{\circ} \mathrm{C}$ for $10 \mathrm{~min}$ followed by 30 (Lactobacillus, Atopobium, G. vaginalis and Veillonella), 35 (Prevotella) or 40 (Bifidobacterium, S. thermophilus) cycles of denaturation at $95^{\circ} \mathrm{C}$ for $15 \mathrm{~s}$; primer annealing at $63^{\circ} \mathrm{C}$ (Lactobacillus, S. thermophilus), $62^{\circ} \mathrm{C}$ (Veillonella), or $60^{\circ} \mathrm{C}$ (Bifidobacterium, Atopobium, Prevotella, G. vaginalis ) for $20 \mathrm{~s}$; extension at $72^{\circ} \mathrm{C}$ for 45 s (Lactobacillus, Atopobium, Prevotella, G. vaginalis, Veillonella), $30 \mathrm{~s}$ (Bifidobacterium), or $15 \mathrm{~s}$ (S. thermophilus) and a fluorescence acquisition step at $85^{\circ} \mathrm{C}$ (Lactobacillus, Atopobium, G. vaginalis, Veillonella, S. thermophilus), $87^{\circ} \mathrm{C}$ (Prevotella) or $90^{\circ} \mathrm{C}$ (Bifidobacterium) for $5 \mathrm{~s}$. DNAs extracted from $L$. acidophilus NCFM, B. longum NCC2705, G. vaginalis ATCC 14018, Prevotella bivia ATCC 29303, Veillonella parvula ATCC 10790, Atopobium vaginae ATCC BAA-55 and S. thermophilus ATCC 19258 were used as standards for PCR quantification. DNAs extracted from vaginal samples were amplified in triplicate for each primer set and the mean value was used for statistical analysis. Data were expressed as ng of DNA of the targeted genus or species per $\mu \mathrm{g}$ of total DNA extracted from the vaginal sample.

\section{Bioplex immunoassay}

Cytokine levels were determined using a multiplexed bead immunoassay. Prior to assay, vaginal samples were concentrated 10 times with Microcon spin devices (YM3, Millipore Corporation, Billerica, MA) and subsequently resuspended in Bio-Plex Assay Buffer. The levels of 27 immune-mediators, 15 cytokines (IL-1 $\beta$, IL1ra, IL-2, IL-4, IL-5, IL-6, IL-7, IL-9, IL-10, IL-12(p70), IL-13, IL-15, IL-17, IFN- $\gamma$, TNF $\alpha$ ), 7 chemokines (MCP1 , MIP-1 $\alpha$, MIP-1 $\beta$, RANTES, Eotaxin, IL-8, IP-10) and 5 growth factors (PDGF-BB, FGF basic, G-CSF, GMCSF, VEGF), were measured using the human ultrasensitive cytokine 27-plex antibody bead kit (Bio-Rad). Assays were performed in 96-well filter plates, as previously described [49]. Briefly, the filter plate was prewetted with washing buffer (Bio-Rad) and the solution was aspirated from the wells using a vacuum manifold (Millipore Corporation). Microsphere beads coated with monoclonal antibodies against the different target analytes were added to the wells. Samples and standards were pipetted into the wells and incubated for $30 \mathrm{~min}$ with the beads. Wells were washed using a vacuum manifold (Millipore Corporation) and biotinylated secondary antibodies were added. After incubation for 30 $\mathrm{min}$, beads were washed then incubated for $10 \mathrm{~min}$ with streptavidin-PE conjugated to the fluorescent protein, R-phycoerythrin (streptavidin/R-phycoerythrin). After washing to remove the unbound streptavidin/R-phycoerythrin, the beads (a minimum of 100 per analyte) were analyzed in the Luminex 200 instrument (MiraiBio, Alameda, CA). The Luminex 200 monitors the spectral properties of the beads to distinguish the different analytes, while simultaneously measuring the amount of fluorescence associated with R-phycoerythrin, reported as median fluorescence intensity. The concentration of the samples was estimated from the standard curve using a fifth-order polynomial equation and expressed as $\mathrm{pg} / \mathrm{ml}$ after adjusting for the dilution factor (Bio-Plex Manager software version 5.0). Samples below the detection limit of the assay were recorded as zero, while samples above the upper limit of quantification of the standard curves were assigned the highest value of the curve. The intra-assay CV including ultrafiltration and immunoassay averaged 19\%. Concentrations of cytokines, chemokines and growth factors were then converted in $\mathrm{pg}$ of the target molecule per $\mu \mathrm{g}$ of total proteins present in the vaginal sample.

\section{Statistical analysis}

Statistical analysis was performed using SigmaStat (Systat Software, Point Richmond, CA). For each subject, variations of the DGGE profiles related to the time points W33 and W37 were analyzed by Pearson correlation. Significant differences in the intensity of each 
DGGE band among all vaginal samples and in the amounts of the bacterial genera and species determined by qPCR were searched by using Wilcoxon Signed Rank Test. This test was also used to analyze differences in cytokines, chemokines and growth factors. A $P$ value below 0.05 was considered statistically significant.

\section{Competing interests}

VSL Pharmaceuticals, Inc. is financing the article-processing charge. The authors declare that they have no other competing interests.

\section{Authors' contributions}

BV performed the study design, analysis and interpretation of the data and the writing of the paper. FC, MC and ST performed DGGE and APCR experiments and statistical analysis of the data. MEB and TC enrolled the subjects and collected the vaginal samples. ES and MCV carried out the Bioplex immunoassay. PB supervised the study. All authors read and approved the manuscript.

\section{Author details}

'Department of Pharmaceutical Sciences, University of Bologna, Bologna, Italy. ${ }^{2}$ Department of Gynecology, Obstetrics and Neonatology, University of Bari, Bari, Italy. ${ }^{3}$ Department of Experimental Biology, University of Bologna, Bologna, Italy.

Received: 6 February 2012 Accepted: 16 October 2012

Published: 18 October 2012

\section{References}

1. Lidbeck A, Nord CE: Lactobacilli and the normal human anaerobic microflora. Clin Infect Dis 1993, 16(Suppl 4):181-187.

2. Donati L, Di Vico A, Nucci M, Quagliozzi L, Spagnuolo T, Labianca A, Bracaglia M, lanniello F, Caruso A, Paradisi G: Vaginal microbial flora and outcome of pregnancy. Arch Gynecol Obstet 2010, 281:589-600.

3. Mattison DR, Damus K, Fiore E, Petrini J, Alter C: Preterm delivery: a public health perspective. Paediatr Perinat Epidemiol 2001, 15(Suppl 2):7-16.

4. Goldenberg RL, Culhane JF, lams JD, Romero R: Epidemiology and causes of preterm birth. Lancet 2008, 371:75-84.

5. Hillier SL, Nugent RP, Eschenbach DA, Krohn MA, Gibbs RS, Martin DH, Cotch MF, Edelman R, Pastorek JG, Rao AV, McNellis D, Regan JA, Carey JC, Klebanoff MA: Association between bacterial vaginosis and preterm delivery of a low-birth-weight infant. The vaginal infections and prematurity study group. N Engl J Med 1995, 333:1737-1742

6. McGregor JA, French Jl: Bacterial vaginosis in pregnancy. Obstet Gynecol Surv 2000, 55(5 Suppl 1):1-19.

7. Beigi RH, Yudin MH, Cosentino L, Meyn LA, Hillier SL: Cytokines, pregnancy, and bacterial vaginosis: comparison of levels of cervical cytokines in pregnant and nonpregnant women with bacterial vaginosis. J Infect Dis 2007, 196:1355-1360.

8. Mattsby-Baltzer I, Platz-Christensen JJ, Hosseini N, Rosén P: IL-1beta, IL-6, TNFalpha, fetal fibronectin, and endotoxin in the lower genital tract of pregnant women with bacterial vaginosis. Acta Obstet Gynecol Scand 1998, 77:701-706.

9. Norwitz ER, Robinson JN, Challis JR: The control of labor. N Engl J Med 1999, 341:660-666.

10. Challis JR, Lockwood CJ, Myatt L, Norman JE, Strauss JF, Petraglia F: Inflammation and pregnancy. Reprod Sci 2009, 16:206-215.

11. Houben ML, Nikkels PG, van Bleek GM, Visser GH, Rovers MM, Kessel H, de Waal WJ, Schuijff L, Evers A, Kimpen UL, Bont L: The association between intrauterine inflammation and spontaneous vaginal delivery at term: a cross-sectional study. PLoS One 2009, 4:e6572.

12. Dubicke A, Fransson $E$, Centini $G$, Andersson E, Byström B, Malmström A, Petraglia F, Sverremark-Ekström E, Ekman-Ordeberg G: Pro-inflammatory and anti-inflammatory cytokines in human preterm and term cervical ripening. J Reprod Immunol 2010, 84:176-185.

13. FAO/WHO: Guidelines for the evaluation of probiotics in food. London, Ontario: Food and Agriculture Organization of United Nations and World Health Organization Working Group report; 2002.

14. Reid $\mathrm{G}$, Bocking $A$ : The potential for probiotics to prevent bacterial vaginosis and preterm labor. Am J Obstet Gynecol 2003, 189:1202-1208.
15. Reid G, Charbonneau D, Erb J, Kochanowski B, Beuerman D, Poehner R, Bruce AW: Oral use of Lactobacillus rhamnosus GR-1 and L. fermentum RC-14 significantly alters vaginal flora: randomized, placebo-controlled trial in 64 healthy women. FEMS Immunol Med Microbiol 2003, 35:131-134

16. Reid G, Anukam K, James VI, van der Mei HC, Heineman C, Busscher HJ, Bruce AW: Oral probiotics for maternal and newborn health. J Clin Gastroenterol 2005, 39:353-354.

17. Rautava S, Kalliomäki M, Isolauri E: Probiotics during pregnancy and breast-feeding might confer immunomodulatory protection against atopic disease in the infant. J Allergy Clin Immunol 2002, 109:119-121.

18. Huurre A, Laitinen K, Rautava S, Korkeamäki M, Isolauri E: Impact of maternal atopy and probiotic supplementation during pregnancy on infant sensitization: a double-blind placebo-controlled study. Clin Exp Allergy 2008, 38:1342-1348.

19. Zhou X, Bent SJ, Schneider MG, Davis CC, Islam MR, Forney L: Characterization of vaginal microbial communities in adult healthy women using cultivation-independent methods. Microbiology 2004, 150:2565-2573.

20. Hyman RW, Fukushima M, Diamond L, Kumm J, Giudice LC, Davis RW: Microbes on the human vaginal epithelium. Proc Natl Acad Sci U S A 2005, 102:7952-7957.

21. Sundquist A, Bigdeli $S$, Jalili R, Druzin ML, Waller S, Pullen KM, El-Sayed YY, Taslimi MM, Batzoglou S, Ronaghi M: Bacterial flora-typing with targeted, chip-based Pyrosequencing. BMC Microbiol 2007, 7:108.

22. Vitali B, Pugliese C, Biagi E, Candela M, Turroni S, Bellen G, Donders GG, Brigidi P: Dynamics of vaginal bacterial communities in women developing bacterial vaginosis, candidiasis, or no infection, analyzed by PCR-denaturing gradient gel electrophoresis and real-time PCR. App/ Environ Microbiol 2007, 73:5731-5741.

23. Oakley BB, Fiedler TL, Marrazzo JM, Fredricks DN: Diversity of human vaginal bacterial communities and associations with clinically defined bacterial vaginosis. Appl Environ Microbiol 2008, 74:4898-4909.

24. Kim TK, Thomas SM, Ho M, Sharma S, Reich Cl, Frank JA, Yeater KM, Biggs DR, Nakamura N, Stumpf R, Leigh SR, Tapping RI, Blanke SR, Slauch JM, Gaskins HR, Weisbaum JS, Olsen GJ, Hoyer LL, Wilson BA: Heterogeneity of vaginal microbial communities within individuals. J Clin Microbiol 2009, 47:1181-1189.

25. Burton JP, Cadieux PA, Reid G: Improved understanding of the bacterial vaginal microbiota of women before and after probiotic instillation. Appl Environ Microbiol 2003, 69:97-101.

26. Devillard E, Burton JP, Reid G: Complexity of vaginal microflora as analyzed by PCR denaturing gradient gel electrophoresis in a patient with recurrent bacterial vaginosis. Infect Dis Obstet Gynecol 2005, 13:25-31.

27. De Backer E, Verhelst R, Verstraelen H, Alqumber MA, Burton JP, Tagg JR, Temmerman M, Vaneechoutte M: Quantitative determination by real-time PCR of four vaginal Lactobacillus species. Gardnerella vaginalis and Atopobium vaginae indicates an inverse relationship between $L$. gasseri and L. iners. BMC Microbiol 2007, 7:115.

28. Biagi E, Vitali B, Pugliese C, Candela M, Donders GG, Brigidi P: Quantitative variations in the vaginal bacterial population associated with asymptomatic infections: a real-time polymerase chain reaction study. Eur J Clin Microbiol Infect Dis 2009, 28:281-285.

29. El Aila NA, Tency I, Claeys G, Verstraelen H, Saerens B, Santiago GL, De Backer E, Cools P, Temmerman M, Verhelst R, Vaneechoutte M: Identification and genotyping of bacteria from paired vaginal and rectal samples from pregnant women indicates similarity between vaginal and rectal microflora. BMC Infect Dis 2009, 9:167.

30. Guandalini S, Magazzù G, Chiaro A, La Balestra V, Di Nardo G, Gopalan S, Sibal A, Romano C, Canani RB, Lionetti P, Setty M: VSL\#3 improves symptoms in children with irritable bowel syndrome: a multicenter, randomized, placebo-controlled, double-blind, crossover study. J Pediatr Gastroenterol Nutr 2010, 51:24-34

31. Brigidi P, Vitali B, Swennen E, Altomare L, Rossi M, Matteuzzi D: Specific detection of Bifidobacterium strains in a pharmaceutical probiotic product and in human feces by polymerase chain reaction. Syst Appl Microbiol 2000, 23:391-399.

32. Pagnini C, Saeed R, Bamias G, Arseneau KO, Pizarro TT, Cominelli F: Probiotics promote gut health through stimulation of epithelial innate immunity. PNAS 2010, 107:454-459. 
33. Stoyancheva GD, Danova ST, Boudakov IY: Molecular identification of vaginal lactobacilli isolated from Bulgarian women. Antonie Van Leeuwenhoek 2006, 90:201-210.

34. Törnblom SA, Klimaviciute A, Byström B, Chromek M, Brauner A, EkmanOrdeberg G: Non-infected preterm parturition is related to increased concentrations of IL-6, IL-8 and MCP-1 in human cervix. Reprod Biol Endocrinol 2005, 3:39.

35. Fortunato SJ, Menon R, Lombardi SJ: Interleukin-10 and transforming growth factor-beta inhibit amniochorion tumor necrosis factor-alpha production by contrasting mechanisms of action: therapeutic implications in prematurity. Am J Obstet Gynecol 1997, 177:803-809.

36. Brown NL, Alvi SA, Elder MG, Bennett PR, Sullivan MH: The regulation of prostaglandin output from term intact fetal membranes by antiinflammatory cytokines. Immunology 2000, 99:124-133.

37. Athayde N, Romero R, Maymon E, Gomez R, Pacora P, Araneda H, Yoon BH: A role for the novel cytokine RANTES in pregnancy and parturition. Am J Obstet Gynecol 1999, 181:989-994.

38. Garcia-Zepeda EA, Rothenberg ME, Ownbey RT, Celestin J, Leder P, Luster AD: Human eotaxin is a specific chemoattractant for eosinophil cells and provides a new mechanism to explain tissue eosinophilia. Nat Med 1996, 2:449-456.

39. Walter J, Tannock GW, Tilsala-Timisjarvi A, Rodtong S, Loach DM, Munro K, Alatossava T: Detection and identification of gastrointestinal Lactobacillus species by using denaturing gradient gel electrophoresis and speciesspecific PCR primers. Appl Environ Microbiol 2000, 66:297-303.

40. Walter J, Hertel C, Tannock GW, Lis CM, Munro K, Hammes WP: Detection of Lactobacillus, Pediococcus, Leuconostoc, and Weissella species in human feces by using group-specific PCR primers and denaturing gradient gel electrophoresis. Appl Environ Microbiol 2001, 67:2578-2585

41. Bassam BJ, Caetano-Anollés G, Gresshoff PM: Fast and sensitive silver staining of DNA in polyacrylamide gels. Anal Biochem 1991, 196:80-83.

42. Heilig HGHJ, Zoetendal EG, Vaughan EE, Marteau P, Akkermans AD, de Vos WM: Molecular diversity of Lactobacillus spp. and other lactic acid bacteria in the human intestine as determined by specific amplification of 16S ribosomal DNA. Appl Environ Microbiol 2002, 68:114-123.

43. Kok RG, de Waal A, Schut F, Welling GW, Weenk G, Hellingwerf KJ: Specific detection and analysis of a probiotic Bifidobacterium strain in infant feces. Appl Environ Microbiol 1996, 62:3668-3672.

44. Tilsala-Timisjärvi A, Alatossava T: Development of oligonucleotide primers from the 16S-23S rRNA intergenic sequences for identifying different dairy and probiotic lactic acid bacteria by PCR. Int J Food Microbiol 1997, 35:49-56.

45. Zariffard MR, Saifuddin M, Sha BE, Spear GT: Detection of bacterial vaginosis-related organisms by real-time PCR for Lactobacilli, Gardnerella vaginalis and Mycoplasma hominis. FEMS Immunol Med Microbiol 2002, 34:277-281.

46. Matsuki T, Watanabe K, Fujimoto J, Takada T, Tanaka R: Use of 16S rRNA gene-targeted group-specific primers for real-time PCR analysis of predominant bacteria in human feces. Appl Environ Microbiol 2004, 70:7220-7228.

47. Matsuki T, Watanabe K, Fujimoto J, Miyamoto Y, Takada T, Matsumoto K, Oyaizu H, Tanaka R: Development of 16S rRNA-gene-targeted groupspecific primers for the detection and identification of predominant bacteria in human feces. Appl Environ Microbiol 2002, 68:5445-5451.

48. Rinttilä $T$, Kassinen A, Malinen E, Krogius L, Palva A: Development of an extensive set of 16S rDNA-targeted primers for quantification of pathogenic and indigenous bacteria in faecal samples by real-time PCR. J Appl Microbiol 2004, 97:1166-1177.

49. Vignali DA: Multiplexed particle-based flow cytometric assays. J Immunol Methods 2000, 243:243-255.

doi:10.1186/1471-2180-12-236

Cite this article as: Vitali et al:: Dietary supplementation with probiotics during late pregnancy: outcome on vaginal microbiota and cytokine secretion. BMC Microbiology 2012 12:236.

\section{Submit your next manuscript to BioMed Central and take full advantage of:}

- Convenient online submission

- Thorough peer review

- No space constraints or color figure charges

- Immediate publication on acceptance

- Inclusion in PubMed, CAS, Scopus and Google Scholar

- Research which is freely available for redistribution

Submit your manuscript at www.biomedcentral.com/submit
C Biomed Central 